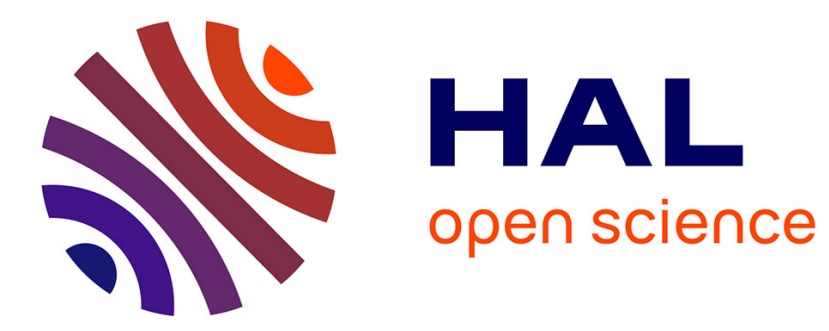

\title{
Positron spur structure emulated by variable energy slow positron beam
}

\author{
Y. Ito, H. Abe, Y. Tabata
}

\section{To cite this version:}

Y. Ito, H. Abe, Y. Tabata. Positron spur structure emulated by variable energy slow positron beam. Journal de Physique IV Proceedings, 1993, 03 (C4), pp.C4-131-C4-133. 10.1051/jp4:1993416 . jpa00251459

\section{HAL Id: jpa-00251459 https://hal.science/jpa-00251459}

Submitted on 1 Jan 1993

HAL is a multi-disciplinary open access archive for the deposit and dissemination of scientific research documents, whether they are published or not. The documents may come from teaching and research institutions in France or abroad, or from public or private research centers.
L'archive ouverte pluridisciplinaire HAL, est destinée au dépôt et à la diffusion de documents scientifiques de niveau recherche, publiés ou non, émanant des établissements d'enseignement et de recherche français ou étrangers, des laboratoires publics ou privés. 


\title{
Positron spur structure emulated by variable energy slow positron beam
}

\author{
Y. ITO, H. ABE* and Y. TABATA*
}

Research Center for Nuclear Science and Technology, The University of Tokyo, Tokai, Ibaraki 319-11, Japan

* Faculty of Engineering, Tokai University, Japan

\begin{abstract}
Variable energy slow positron beam was used to probe the positronic spur processes in polymers: low density polyethylene and a polyimide (Kapton). A fraction of the injected positrons was re-emitted as positron or positronium, whose fraction was dependent on the energy of injected positrons. The energy of the re-emitted positrons could become quite large, even larger than the band-gap energies of the substance. This was considered to be the result of charge-up effect. This effect may provide a new concept for a "field assisted slow positron moderator".
\end{abstract}

\section{Introduction}

Re-emission of positrons and positronium from the surfaces of ionic crystals $(1)$ and solid rare gases (2) are well recognized. Since the re-emission should take place when the terminal positron spur is formed close to the surface, one may emulate the positron spur structure by detailed studies of the re-emission yield and re-emission energies. It is already well recognized that the re--emission yield becomes smaller when the energy of the injected positrons becomes larger. This is because the terminal positron spurs are formed deeper from the surface. We have tried to apply this kind of measurements to probe the spur structures in polymers.

\section{Exper imental}

The experimental set-up is illustrated in Fig.1. Positrons with an energy $V_{\mathrm{B}}$ are injected into the sample mounted on the metal sample holder which is biased a potential $V_{s}$ against the ground. $V_{s}$ was scanned from -60 to $+60 \mathrm{~V}$ maintaining a condition that the impinging positron energy (Ep $=V_{B}-V_{s}$ ) is constant. Ep was varied from 200 to $1800 \mathrm{eV}$. Total counts of the annihilation radiation was measured with a Ge solid state detector. Thus any decrease in the counting rate is regarded as the re-emission either as positron or positronium. The thickness of the polymer

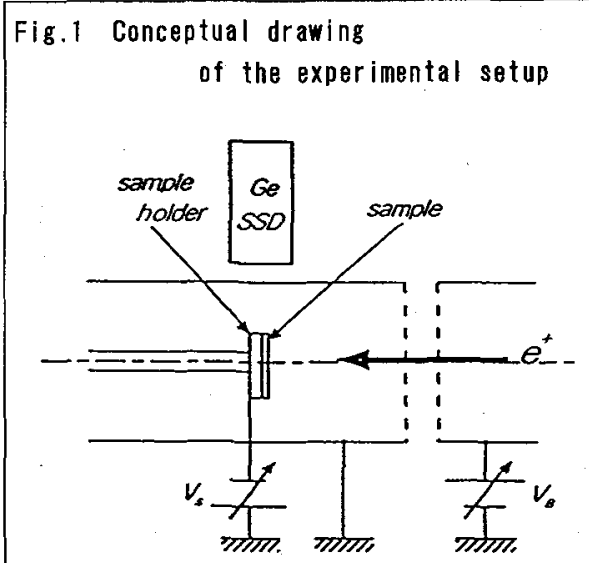


Fig.2 Results of one run of measurements for LDPE and Kapton
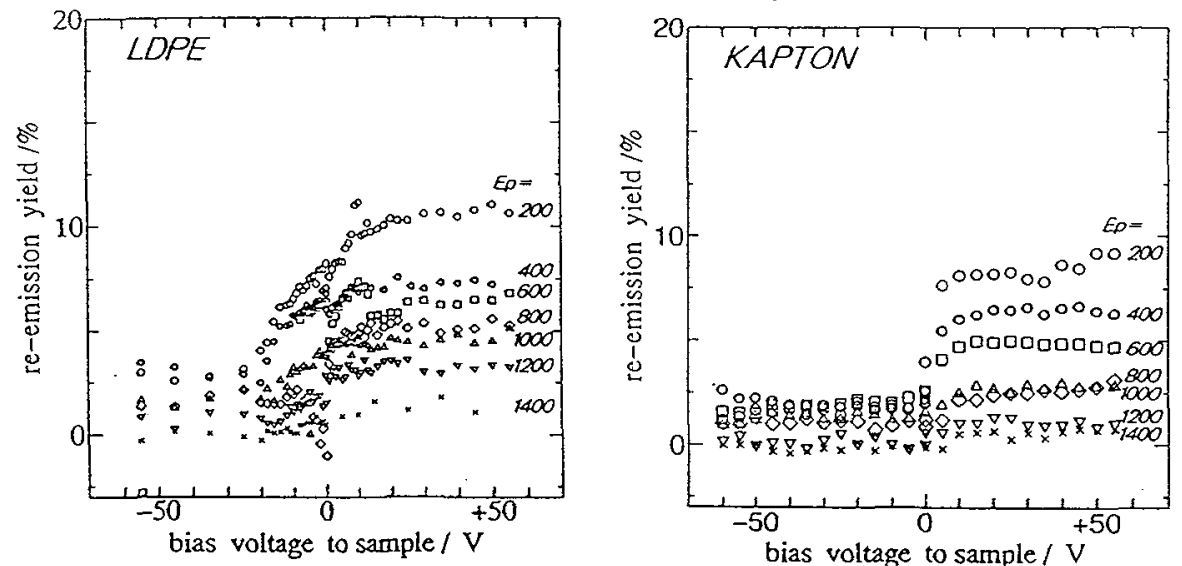

films was 7-9 $\mu \mathrm{m}$ for both low density polyethylene and polyimide (Kapton). In this kind of experiments using insulators as the samples, the potential of the sample is always the matter of problem. If the polymer films are regarded to be simply placed in the electric field, however, the electric potential in them can be calculated by considering the dielectric constant $\varepsilon$ in a way that the distance $r$ in the polymers virtually equals the distance $\varepsilon r$ in vacuum. Since the thickness of the polymers is small, this does not give substantial deviation of the sample potential from that of the sample holder. If there is space charge in the polymer the potential is affetcted, but it can be calculated if the location of the charge were known.

Kapton is a typical polyimide for which long-lived o-Ps component is not observed. ${ }^{(3)}$ In order to test the data reproducibility, more than three successive runs of experiments were performed for both LDPE and Kapton.

\section{Results and Discussion}

Re-emission yields are plotted in Fig.2 against the sample bias voltage with Ep as a parameter. For negative sample biases positrons are retarded back to sample, and for positive sample biases the positrons are accelerated toward vacuum. In IDPE a substantial fraction of positrons are re-emitted even when the sample was negatively biased, suggesting re-emission of energetic positrons. But this is not due to something like "band-gap energy" positrons as will be discussed later. The re-emission yield becomes larger for smaller impinging positron energies both for positive bias and negative bias regions. The re-emission in the negative bias regions corresponds to re-emission as Ps. Thus the data for Kapton implies that Ps can be re-emitted from the surface even when Ps formation is not observed in the bulk of Kapton. This is an important result in understanding the mechanism of Ps formation and is related to our report to this workshop. ${ }^{(3)}$ In brief, Ps formation in the bulk is inhibited because the energy levels of $\mathrm{e}^{-}$and/or $\mathrm{e}^{+}$are low and that of Ps in the pores are high. When the positron spurs are formed near surface, however, the energy condition for Ps formation becomes favorable because of the existence of large open space.

Fig. 3 and Fig. 4 summarize three successive measurements like Fig.2 for LDPE and Kapton, respectively. The data of Fig.2 corresponds to the run $2: \square$. It is seen that both the re-emission yield and the maximum energy of re-emission increase according to the time sequence of the measurements. Apparently the re-emission yield and the energy of re-emission change quite easily, and radiation effects or charge-up effects are responsible 
for them. Since the same things are taking place for both IDPE (susceptible to radiation damage) and Kapton (radiation resistant), charge-up effect is more probable. The intrinsic re-emission, i.e re-emission in the condition of free of charge up effect, will thus be close to the data of fresh sample (1:O). Intrinsic re-emission yield (positron and Ps included) is therefore less than about $5 \%$. It is noteworthy however that a substantial fraction of positrons become emitted even at high implantation energies. This is a re-emission assisted by internal field of positive charge created due to positron annihilation in the sample. There is some hope to design an efficient moderator based on this mechanism.

Fig.3 Re-emission yield and the maximum energy of emitted positrons for LDPE

1,2 and 3 indicate the time sequential order of the experiments, 1 is the data just after starting the experiments. Radiation effect or charge-up effect may be small for the run 1, and are substantial for run 3 .
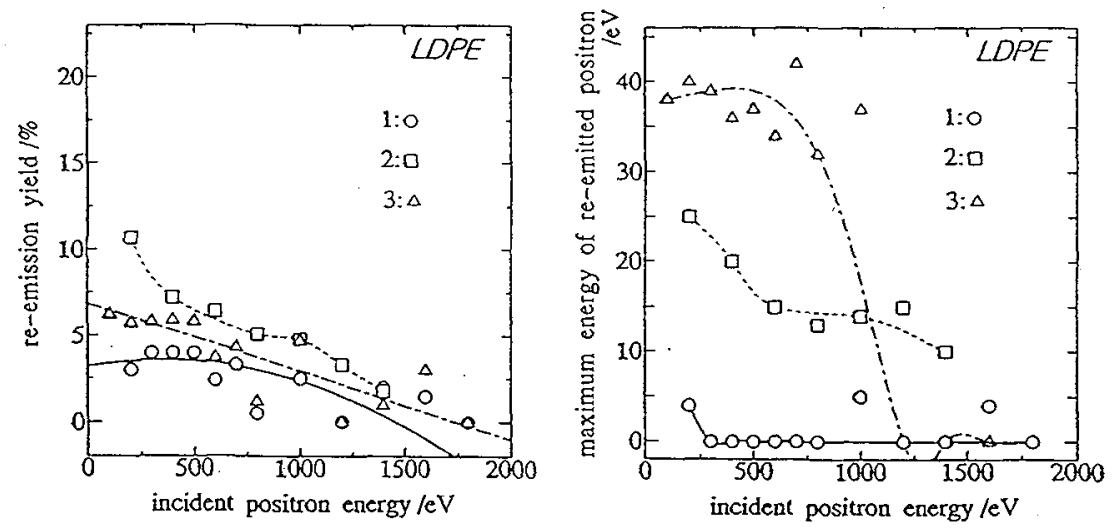

Fig.4 Same as Fig.4 for Kapton
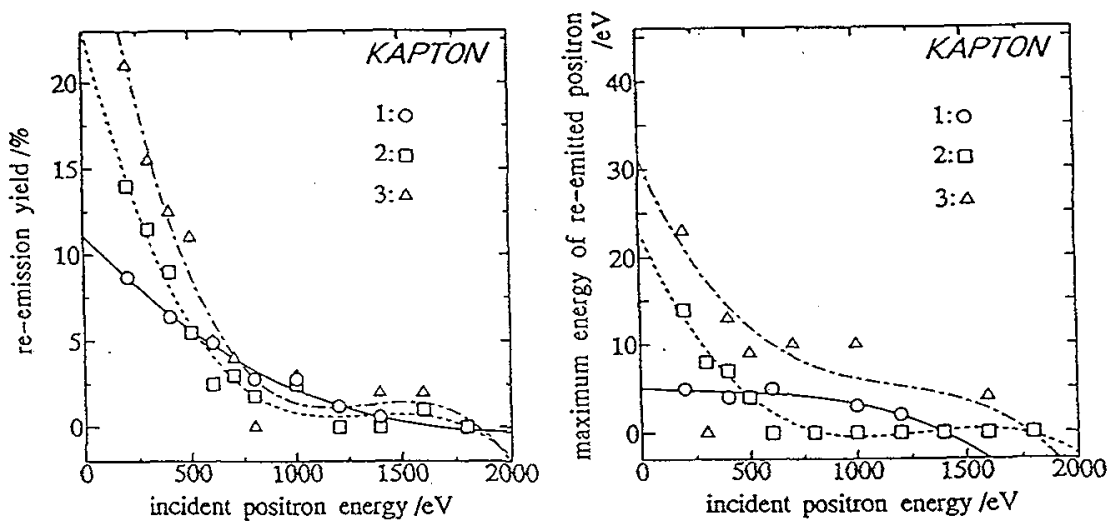

/1/ Mills,A.P. Jr. and Crane, W.S. Phys. Rev. Lotters, 53(1984)2165

/2/ A.P.Mills, Jr. and Gullikson,M, Appl. Phys. Lett., 49(1986)1121

/3/ TT0 et al.. "Interplay between electron affinity and free volume on Ps formation in polymers", this workshop 